\title{
CONDITION ASSESSMENT OF LOWER ROADWAY LAYERS FOR PAVEMENT MANAGEMENT SYSTEMS
}

\author{
Andrzej POŻARYCKI \\ Department of Roads, Streets and Airports, Faculty of Civil and Environmental Engineering, \\ Poznan University of Technology, Piotrowo st. 5, PL-60-965 Poznan, Poland
}

Received 03 Feb 2013; accepted 26 Apr 2013

\begin{abstract}
The process of selecting road maintenance technologies for the Pavement Management System (PMS) can use road pavement moduli of deformation as the substantiating information. Assessment criteria based on either pavement or base course moduli of deformation have strong empirical underpinning, since the stiff plate bearing testing (SPBT) is commonly used worldwide. This paper discusses potential practical applications of plate bearing test numerical simulation based on Falling Weight Deflectometer (FWD) deflection data, and theoretical model based on flexible pavement. It was proven that including a pavement model with stress dependency, the simulated second load-displacement curves meet reliably plate bearing in-situ test conditions for different layers of either subgrade or base courses of road pavement. This methodology is feasible by classifying technical condition of each lower layer of road pavement against requirements towards new pavements.
\end{abstract}

Keywords: subgrade, crushed aggregate base course, pavement management systems, stiff plate bearing test simulation, FWD static pavement deflections, pavement subgrade and base course condition.

\section{Introduction}

Various forms of the integration of knowledge-based, decision support or other systems have a potential in different scientific research areas (Zavadskas et al. 2010). In case of Pavement Management Systems, the number of factors that affects decision-making arises the problems with large numbers of scenarios where multi-attribute decision-making methods would be naturally applicable considering the (Zavadskas et al. 2008) conclusions. Looking for a better global pavement structure indicator someone should include the lower parts of pavement systems as well.

Bearing capacity of existing pavement condition evaluation is more complex than in case of newly built roads. An attempt to reliably assess correlation between test results of unbound layer load-bearing capacity obtained through conventional testing and Portable Falling Weight Deflectometer (PFWD) was made by authors of the paper (Rafiei et al. 2012; Huang, Kang 2010). Unfortunately, applications of such devices, comprehensive laboratory experiments (Rahim, George 2005; Chang et al. 2010) or other in-situ detailed investigations (Vennapusa et al. 2012), are limited to point and local measurements, and are practically redundant in Pavement Management Systems (PMS). Even the most sophisticated based ANN methods for pavement parameters identi- fication (Gopalakrishnan 2010; Zaman 2010) fail without reliable input parameters and large enough databases. In those cases, well-proven requirements should be used, so that the in-situ determined values were comparable with the particular PMS procedures (Aavik et al. 2006). Such as used criteria based on moduli of deformation $E v 2$ or equivalent modulus, seems to be well established within engineering field (Butkevičius et al. 2007).

Infrastructure engineering staff could not have the certainty, pavement deflection measurements for PMS database would always be possible using the same device. Hence, identifying the relationship between test data obtained using different pavement non-destructive and invasive testing devices is one of key engineering tasks for a correct pavement diagnosis (Šiaudinis 2006). In this context, in-depth analysis into conditions of base courses, subgrade and surface courses is required to correctly assign macroscopic pavement damage to underlying reasons (Le et al. 2011).

An interesting review of static and dynamic deflection testing methods for selected pavement layers was presented by authors of the paper (Bertuliene et al. 2010; Bertuliené 2012). It concluded that developing new methods of interpreting deflection test data is essential, regardless of relationships it defines between pavement deflection measured by beam static analysis, ZORN dy-

Corresponding author: Andrzej Pożarycki

E-mail: andrzej.pozarycki@put.poznan.pl 
namic plate bearing test and two different Falling Weight Deflectometer (FWD) devices. It is necessary to develop relationships not only for determining reduction factors but also for purposes of comprehensive analyses, which would factor in correct layer thickness, pavement layer structure and testing temperature.

Research results presented in paper (Talvik, Aavik 2009) rejected the hypothesis relationship between different type pavement damage (fractures, ruts) and parameters used in pavement diagnosis i.e. surface curvature index (SCI), base damage index (BDI) and base curvature index (BCI). Acceptable values of correlation were observed between equivalent modulus and SCI and BDI parameters, which are acknowledged as best descriptors of top pavement layer conditions. The relationship between BCI deflection basin parameter and pavement equivalent modulus was identified as much weaker. Paper (Park et al. 2011) argued against that conclusion. It stated the $\mathrm{BCI}$ indicator is correctly correlated with pavement layer modulus backcalculated using FWD deflection data. Ultimately, deflection curve parameters based on FWD deflection data are a practical indicator of pavement structural health. The problem of accurate diagnosis of pavement layer modulus of elasticity based on FWD deflection data was addressed among other by the paper (Yi et al. 2010). It presented an analysis proving the value of load amplitude is far less significant for identification results than correctly estimated pavement layer thickness. Pavement condition evaluation of test section described by Vaitkus et al. (2012) was underpinned by pavement equivalent modulus. Pavement design alternatives in good and bad structural condition in-service for 5 years were identified based on said indicator.

In line with assumptions, the global indicator determines final condition evaluation in majority of PMS systems. Several most popular PMS methodologies were reviewed in the paper of Ferreira et al. (2011). Most recognition from authors received the AASHTO model predicting pavement quality index (PSI). The base course condition expressed by the value of the resilient modulus is often an element of the PSI indicator in that model. It was emphasised that especially the aforementioned model was particularly sensitive to pavement parameters. Notice, the influence of stress on the value of moduli identified for layers, bounded pavements and subgrades is often overlooked in result set analyses. The problem of non-linear relationships between those pavement layers illustrated with an example of different load configurations applied to pavement layers was described in paper of Kim and Lee (2011).

\section{Background of PMS preventive maintance}

The PMS philosophy which stems for improving the quality and performance of pavement maintenance projects is usually based on either the financial consequences of delaying a preventive maintance or based on the technical condition of the pavement. For finding optimum strategies when maintaining pavements in serviceable condition, the following parameters are mainly considered:

- Pavement roughness or ride quality;

- Surface distress, Rutting, Cracking;

- Skid resistance;

- Structural capacity.

In this work the main attention is related to part of the global performance serviceability index, which is responsible for structural bearing capacity of pavement. By the Research Centres in the world, pavement damage indicators are formulated in many ways, including deflection basin parameters (DBPs), effective moduli, and stress/strain parameters (Xu et al. 2002; Kim 2002). When applied to field testing, using the FWD deflection measuring device, pavement layer condition can be estimated at least by calculation: SCI, BDI, BCI, AUPP (Area Under Pavement Profile indicator), SSR (Subgrade Stress Ratio). Kim (2002) developed the series of predictive models for such critical pavement evaluation. As an example one can consider the relationship (1) which gives the subgrade strength estimation for aggregate base treated flexible pavements. Higher values of BDI indicate poorer subgrade strength:

$$
\begin{aligned}
\log (B D I)= & -0.7272 \cdot \log \left(E_{A C}\right)-1.8812 \cdot \log \left(H_{A C}\right)- \\
& 0.1073 \cdot \log \left(E_{R i}\right)+4.3299,
\end{aligned}
$$

where: $E_{A C}$ - stiffness modulus of AC courses package; $H_{A C}$ - thickness of AC courses package; $E_{R i}$ - subbase modulus.

Widely also used load rating conditions for PMS reduced only to criterion of the maximum pavement deflections sometimes leads to improper strategy of preventive maintenance and pavement rehabilitation treatments. The consequence of the strengthening of the existing pavement just by using a new asphalt layers package in a situation where the $E v 2$ values are far below requirements will result in of accelerated pavement destruction (Fig. 1).

Generally, it should be noted that the above indicators are a very successful attempts to evaluate the lower layers technical condition of roads for the needs of PMSs. Anyway, the real barrier to the dissemination of such an approach can be a criterion (namely the establishment of admissible limit values). As long as the country-specific guidelines do not define the limit requirements for such

test 33, km 14+590: WIDTH OF ROADWAY, $m$

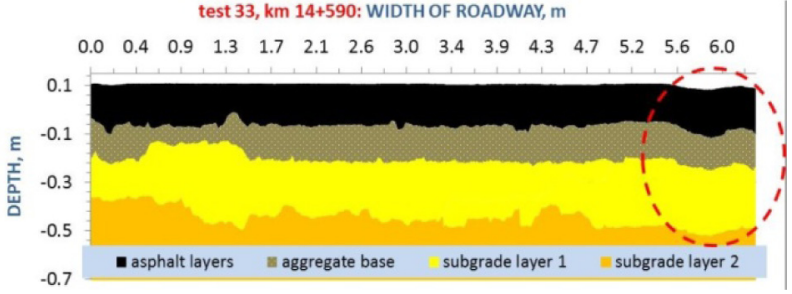

Fig. 1. An example of technical condition of the lower pavement layers after 3 years of pavement serviceability since the rehabilitation by using only a new asphalt layers package 
indicators as e.g. BDI or, the definitions of critical pavement response is rather the result of using of "imported" fatigue criteria than of local ones, search for new measures of road technical assessment is obviously justified.

Notice, in some countries (Germany, Lithuania, Poland, France) evaluation criteria for pavement base courses and subgrades have strong empirical underpinning based on stiff plate bearing (SPB) test in common use worldwide. For this example, in Poland, the following criteria apply:

- Subgrade/Improved subgrade, Ev2 $\geq 120 \mathrm{MPa}$;

- Base course, Ev2 $\geq 150 \mathrm{MPa}$.

Literature review also proves that test results obtained through falling weight tests (FWD, HWD) are mostly used to estimate equivalent moduli for elastic half-space pavement models given by:

$$
E=\frac{P \cdot D}{l} \cdot\left(1-\mathrm{v}^{2}\right)
$$

where: $E$ - equivalent modulus of elasticity; $P$ - vehicle wheel pressure to the pavement $(\mathrm{Pa}) ; D$ - diameter of the plate $(\mathrm{m}) ; l$ - forced pavement deflection $(\mathrm{m})$; $v$ - Poisson's ratio.

Consequently, in order to determine correlation between identification routine results and modulus of deformation appropriate reduction factors have to be assumed. Literature is full of concepts how to determine relationships between modulus of elasticity investigated under different conditions and using different methodologies.

\section{Enhanced FWD data analysis as a indicators for subgrade and base condition evaluation in PMS}

Bearing in mind the above mentioned not only the DBPs are available from deflection basin measurements. The author proposes an original stiff plate bearing (SPB) test simulation based on (a) FWD deflection data and (b) theoretical model of pavement that is built afterwards as the results of inverse analysis are already known. The tested hypothesis is: analytical value of the modulus of deformation for selected pavement layers based on theoretical stiff plate bearing test simulation is consistent with in-situ test results provided error level is acceptable in PMS engineering practice.

Since the method uses the generally accepted engineering tools for pavement mechanics analysis, method is not site specific. More importantly, the state of the lower pavement layers can be assessed in comparison to the criteria that have strong empirical base. The author is confident the presented methodology is well-suited for PMS needs, since it uses PMS databases more efficiently to a broader extent.

\section{The concept of stiff plate bearing test simulation}

Simplified approach to backcalculated results of identification routines suggests values of the modulus of elasticity could be perceived as values of the modulus of deformation. When evaluating road pavement subgrade condition, because of stress sensitive layers this simpli-

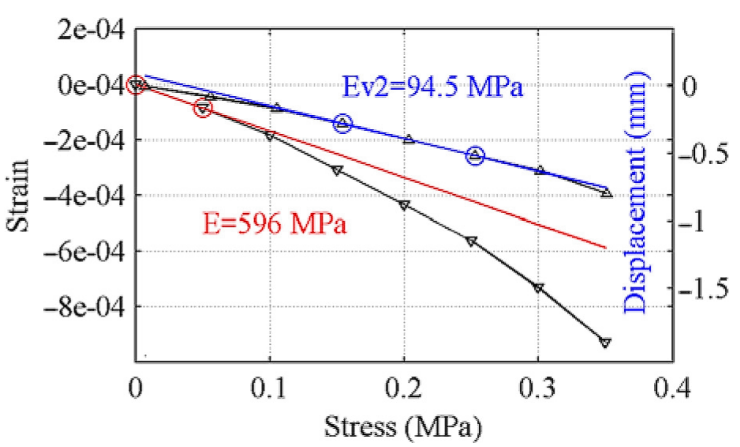

Fig. 2. The modulus of elasticity and the modulus of deformation

fication is often ill-founded and leads to errors (Fig. 2). Generally, commonly used formula for stress sensitive layers, provides definition of secant modulus of deformation (Fig. 2) which for half space with circular stiff plate loading is given by:

$$
E v 2=\frac{3}{4} \cdot \frac{\Delta q}{\Delta w} \cdot D
$$

where: $E v 2$ - modulus of deformation; $\Delta q$ - stress range describing secant; $\Delta s$ - respective vertical displacement range $(\mathrm{mm}) ; D$ - diameter of the stiff plate $(\mathrm{mm})$.

Thus, the concept boils down to determining displacement curves across the surface of selected pavement layer using FWD deflectometer, 7 geophones $(0,300$, $600,900,1200,1500 \mathrm{~mm}$ spacing) and registration of full loading/displacement history.

Because FWD testing uses dynamic loading, the first step is to convert values of dynamic load induced deflections to values of pavement deflection under static load. The frequency response function (FRF) described in paper (Westover et al. 2007) was used in the Mathematica Wolfram Research 8.0.1. software:

$$
F R F_{k}\left(f_{m}\right)=\frac{W_{k}\left(f_{m}\right)}{Q_{k}\left(f_{m}\right)},
$$

where: $F R F_{k}\left(f_{m}\right)$ - frequency response function for the $k^{\text {th }}$ geophone; $W_{k}\left(f_{m}\right), Q_{k}\left(f_{m}\right)-$ Fast Fourier Transform (FFT) applied to the falling-weight deflection $w_{k}(t)$ and force $q(t)$ respectively, to obtain frequency-domain representation.

Knowing the FRF curve as function of frequency, allows determining static pavement response by calculating the function for frequency equal naught (Fig. 3).

Provided dynamic FWD loading is defined in that manner, inverse analysis can use static pavement models. Pavement model using finite element method was employed for identification calculations. Bearing in mind experiences described in the paper (Kim, Lee 2011), a simplified version of universal model was used for modelling subbase pavement layers resilient moduli:

$$
M r=C \cdot\left(\frac{\sigma}{p_{a}}\right)^{-n},
$$




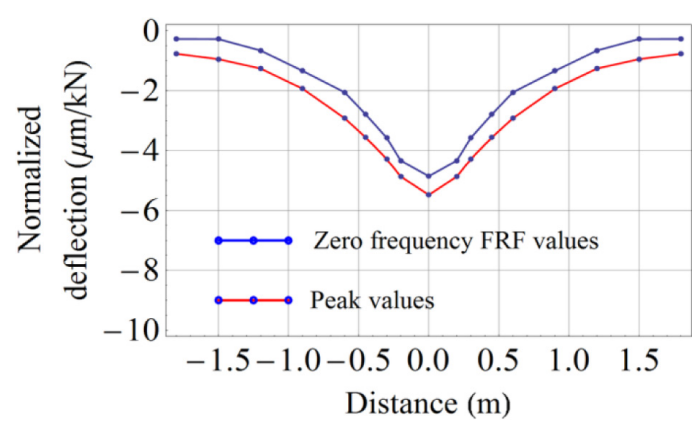

Fig. 3. "Static" and "dynamic" deflection basins

where: $M r$ - resilient modulus; $C, n$ - backcalculated coefficients; $\sigma$ - bulk modulus in the case of aggregate layers modelling and deviator stress for subgrade and cement stabilization layers; $p_{a}$-reference pressure $(0.1 \mathrm{MPa})$.

Finally having identified values of moduli from deflection basin measurements, the core step of presented methodology follows. The plate bearing test is simulated for selected pavement layer (subgrade/improved subgrade or base course) by building pavement models adequate to searched for parameters. Depending on investigated pavement layer - in line with previously referenced standard the value of modulus of deformation Ev2 is calculated from formula (3) for the following ranges:

- Subgrade: $\Delta q=0.05 \div 0.15 \mathrm{MPa}$;

- Improved subgrade: $\Delta q=0.15 \div 0.25 \mathrm{MPa}$;

- Aggregate Base: $\Delta q=0.25 \div 0.35 \mathrm{MPa}$.

Presented concept has been verified in subsequent items.

\section{Validation of layers condition assessment procedure using the test section data}

\subsection{The test section characteristics}

Comparative analysis was carried out using test results for typical polish heavily trafficked flexible pavement solution. The study used a uniform road section with a length of $245 \mathrm{~m}$. To a depth of $1 \mathrm{~m}$ below the bottom of the pavement structure, there was no groundwater table. Sandy clay was found in test section subgrade. The subgrade was improved through both soil stabilisation and mechanically stabilised crushed aggregate technology. Mean depth of stabilised layer was $22 \mathrm{~cm}$ and obtained strength classified as $C_{1.5 / 2.0}$. The next layer was built from mechanically stabilised crushed aggregate $40 \mathrm{~cm}$ thick and $0 / 63 \mathrm{~mm}$ granulation. The base course $(22 \mathrm{~cm}$ deep) was produced as single layer, also mechanically stabilised crushed aggregate base course with continuous granulation. The package of asphalt concrete layers consists of HMAC courses $25 \mathrm{~cm}$ thick and SMA surface course $4 \mathrm{~cm}$ thick.

FWD tests were carried out in-situ at each stage of road pavement construction (Fig. 4). On particular layers of analysed pavement, the researches were carried out by SPB method, in an amount of 10 tests per each layer.

In the same places, starting from the Level: " 0 " until to the surface of the SMA wearing course, FWD tests were also performed (Fig. 5).

\subsection{Inverse analysis}

Listed below are key parameters assumed for purposes of identification by inverse analysis.

- Level: 0 (CRUSHED AGgREGATE BASE COURSE), 3 force drops, target force $\mathrm{F}=30 \mathrm{kN}^{*}$, seed modulus for inverse analysis 400, 100, $20(\mathrm{MPa})$;

- Level: I (HMAC BASE COURSE-STAGE 1), 3 force drops, target force $\mathrm{F}=50 \mathrm{kN}$, seed modulus for inverse analysis 15000, 400, 100, 20 (MPa);

- Level: II (HMAC BASE COURSE-STAGE 2), three force drops, target force $\mathrm{F}=50 \mathrm{kN}$, seed modulus for inverse analysis 15000, 400, 100, 20 (MPa);

- Level: III (HMAC WEARING COURSE), 3 force drops, target force $\mathrm{F}=50 \mathrm{kN}$, seed modulus for inverse analysis 15000, 400, 100, $20(\mathrm{MPa})$;

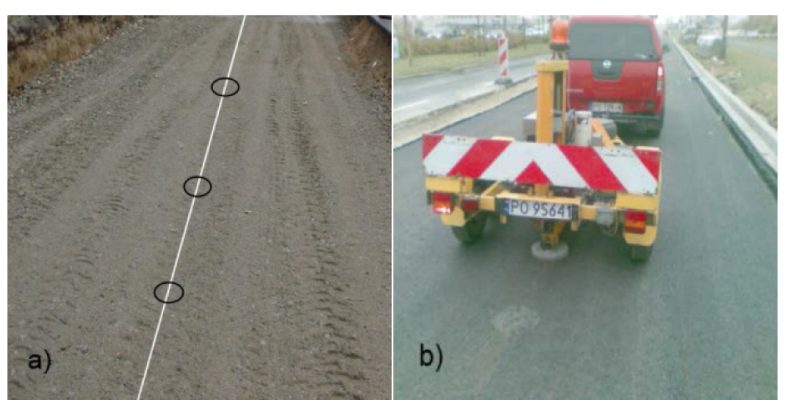

Fig. 5. Surfaces of layers prepared for FWD testing:

a) Crushed aggregate base course; b) HMAC base course

\footnotetext{
SPB - stiff plate bearing test location

FWD - falling weight deflectometer measurements
}

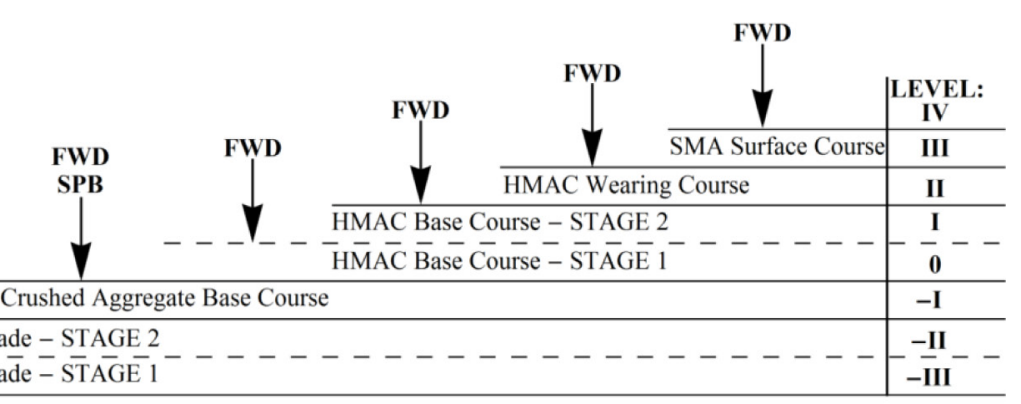

Subgrade (Sandy clay)

Fig. 4. Analysed pavement structure with marked test points (SPB tests and FWD measurements) 
- Level: IV (SMA SURFACE COURSE), 3 force drops, target force $\mathrm{F}=50 \mathrm{kN}$, seed modulus for inverse analysis 15000, 400, 100, $20(\mathrm{MPa})$.

*) Target force was reduced to $30 \mathrm{kN}$ only for FWD tests on Crushed Aggregate Base Course. It stems from measuring range of FWD geophones, which according to technical specification is $+/-2 \mathrm{~mm}$.

Inverse analysis results of identification routines for all FWD testing locations are displayed in Table 1.

Table 2 displays averaged values of identified $C$ and $n$ coefficients for pavement subgrade across the entire test section, collated according to subsequent FWD testing locations.

Subgrade bearing capacity could be misjudged looking at values of the resilient modulus (Table 1), should stresses dependency be neglected. The greater the bituminous layer thickness the lower stresses span across the subgrade in stress sensitive layers, thus the higher value of the $E$ modulus.

\subsection{SPB test simulation $-E v 2$ values}

Due to non-zero values of the $n$ parameter, the simplest formula which partially factors in realistic material characterizations in subgrade is the value of the modulus of deformation $E v 2$. In line with tested methodology, identified pavement layers' parameters were used to build static models in order to simulate plate bearing test conditions (Fig. 6).

\subsubsection{Subgrade condition analysis}

Test section plate bearing tests concluded (Fig. 7) that across the entire analysed section values of the subgrade moduli $E v 2$ э $<8 \div 30>(\mathrm{MPa})$. Vector of load was $q=(0,0.05,0.10,0.15,0.20,0.25,0.30,0.35) \mathrm{MPa}$. For substantial subgrade subsidence (for $E v 2 \leq 15 \mathrm{MPa}$ ), the maximum applied loading during testing was $0.25 \mathrm{MPa}$.

Following the methodology, identified subgrade parameters were used to build static, elastic half-space models simulating plate bearing test conditions. The moduli were obtained by assuming mean $C$ and $n$ subgrade parameters as per Table 2, for individual values of vector of load $q$ in stress sensitive layers model. Integral form of load given by below equation was employed - model load as per plate bearing test:

$$
q(r)=a \cdot \frac{P}{\pi \cdot a^{2}} \cdot \int_{0}^{\infty} J_{0}(k \cdot r) \cdot \sin (k \cdot a) d k .
$$

Load-displacement curves describing subgrade deformation under second cycle of loading, compared with extreme results of in-situ plate bearing test are shown in the Figure 8.

Values of the Ev2 for subgrade were computed (Fig. 9) after theoretically determined were loaddisplacement curves for each instance of test location (Level: 0, I, II, III, IV). Calculations using the relationship (3) were confined to $\Delta q=0.05 \div 0.15 \mathrm{MPa}$.

\subsubsection{Improved subgrade and aggregate base courses condition analysis}

For purposes of the next layers condition assessment, Figure 10 displays other analytical values of Ev2. Results were produced by plate bearing test simulation for the following layers which were tested in-situ:

- Level: 0, (CRUSHED AGGREGATE BASE COURSE), tests on base course $22 \mathrm{~cm}$ thick;

- Level: -I, (IMPROVED SUBGRADE STAGE 2) measurements on crushed aggregate mechanically stabilised course $40 \mathrm{~cm}$ thick;

- Level: -II, (IMPROVED SUBGRADE - STAGE 1), measurements on cement stabilised soil course $22 \mathrm{~cm}$ thick.

Table 3 displays identified mean coefficient values for stress sensitive layers included in analysed model.

Test points for plate bearing tests are also shown on Figure 4. Values of $E v 2$ for concrete-stabilised and crushed aggregate base courses were calculated in line with previously given assumptions, at peak load $q=0.35 \mathrm{MPa}$.

\section{Results and discussion}

Improved subgrade with analysed here pavement structure has to satisfy the condition $E v 2 \geq 120 \mathrm{MPa}$ (Fig. 4, Level: -I) in accordance with Polish design guidelines. The probability of achieving required moduli value on surface of improved subgrade is $\mathrm{P}(E v 2 \geq 120 \mathrm{MPa})=0.65$ (normal distribution $\mathrm{N}[137,32]$ ), based on quantile assessment of SPB test results (Fig. 11).

Minimum required value of modulus of deformation on the surface of Crushed Aggregate Base Course (Fig. 4, Level: 0) is $150 \mathrm{MPa}$. Tests carried out on that layer, produced again the probability $\mathrm{P}(E v 2 \geq 150 \mathrm{MPa})=0.65$. Then the normal distribution parameters are $\mathrm{N}[167,44]$. Confidence intervals determining reliability of in-situ SPB testing results are relatively wide. On the other hand, values of $E v 2$ based on FWD testing results on individual layers of analysed pavement fluctuate around required, in-situ measured SPB test values. The distance between FWD testing surface and surface of identification also has a notable influence on modulus of deformation. In general, the greater the distance between FWD testing surface and the surface modulus of deformation is calculated against, the lower is its value.

All analytical values of the modulus of deformation calculated based on FWD deflection data fall within $90 \%$ confidence interval determined by the plate bearing test results. The minimum modulus of deformation condition on improved subgrade course is satisfied looking at Figure 10b illustrations and given the values produced by function approximating Ev2 measurements. However, subgrade moduli of deformation based on FWD testing on the SMA Surface Course (Fig. 4, Level: IV) had values of bottom confidence interval bounding curve. Hence, related mean value of $E v 2$ does not satisfy the minimum bearing 
Table 1. Inverse analysis parameters identification results of selected pavement layers based on deflection basin measurements

\begin{tabular}{|c|c|c|c|c|c|c|c|c|c|c|c|}
\hline \multirow{3}{*}{$\begin{array}{l}\text { FWD } \\
\text { measurements } \\
\text { location }\end{array}$} & \multicolumn{4}{|c|}{ Subgrade } & \multicolumn{3}{|c|}{$\begin{array}{c}\text { Cement Stabilised Course } \\
\mathrm{C}_{1.5 / 2.0}, \text { (Improved } \\
\text { Subgrade) }\end{array}$} & \multicolumn{3}{|c|}{$\begin{array}{l}\text { Crushed Aggregate Base } \\
\text { Course } 0 / 63 \mathrm{~mm}\end{array}$} & \multirow[t]{3}{*}{ RMS } \\
\hline & Parameter $\rightarrow$ & \multirow{2}{*}{$\mathrm{C}$} & \multirow{2}{*}{$\mathrm{n}$} & \multirow{2}{*}{$\mathrm{E}$} & \multirow{2}{*}{$\mathrm{C}$} & \multirow{2}{*}{$\mathrm{n}$} & \multirow{2}{*}{$\mathrm{E}$} & \multirow{2}{*}{$\mathrm{C}$} & \multirow{2}{*}{$\mathrm{n}$} & \multirow{2}{*}{$\mathrm{E}$} & \\
\hline & $\mathrm{Km} \downarrow$ & & & & & & & & & & \\
\hline Level: 0 & \multicolumn{11}{|c|}{ CRUSHED AGGREGATE BASE COURSE $(22 \mathrm{~cm}), \mathrm{F}=30 \mathrm{kN}$} \\
\hline 1 & $0+150$ & 30.1 & -0.36 & 62.9 & 132.3 & -0.07 & 152.3 & 265.2 & 0.09 & 200.3 & 2.17 \\
\hline 2 & $0+160$ & 39.6 & -0.33 & 74.7 & 218.9 & -0.21 & 325.6 & 316.1 & 0.29 & 181.7 & 4.03 \\
\hline 3 & $0+180$ & 123.3 & -0.13 & 155.1 & 104.6 & -0.50 & 247.8 & 260.7 & 0.15 & 189.2 & 3.53 \\
\hline 4 & $0+200$ & 47.6 & -0.29 & 81.5 & 317.5 & -0.21 & 465.5 & 236.8 & 0.26 & 156.4 & 5.66 \\
\hline 5 & $0+247$ & 41.5 & -0.32 & 77.1 & 210.0 & -0.23 & 325.3 & 311.4 & 0.27 & 184.3 & 5.81 \\
\hline 6 & $0+297$ & 31.9 & -0.29 & 58.2 & 197.2 & -0.16 & 273.3 & 279.7 & 0.20 & 181.2 & 3.44 \\
\hline 7 & $0+320$ & 31.2 & -0.35 & 64.7 & 112.8 & -0.13 & 147.1 & 209.9 & -0.03 & 218.1 & 6.21 \\
\hline 8 & $0+344$ & 29.3 & -0.34 & 61.3 & 68.1 & -0.06 & 77.4 & 259.8 & -0.03 & 271.8 & 5.65 \\
\hline 9 & $0+366$ & 27.4 & -0.32 & 55.4 & 113.2 & -0.08 & 134.6 & 250.8 & -0.02 & 257.8 & 4.70 \\
\hline 10 & $0+390$ & 41.9 & -0.25 & 68.8 & 175.9 & -0.17 & 244.9 & 215.3 & 0.13 & 163.3 & 3.92 \\
\hline Level: I & \multicolumn{11}{|c|}{ HMAC BASE COURSE $(9 \mathrm{~cm}), \mathrm{F}=50 \mathrm{kN}$} \\
\hline 1 & $0+150$ & 28.0 & -0.43 & 65.6 & 178.9 & -0.03 & 189.6 & 169.0 & 0.02 & 160.5 & 0.87 \\
\hline 2 & $0+160$ & 33.9 & -0.40 & 75.5 & 193.6 & -0.09 & 231.1 & 207.7 & 0.02 & 197.1 & 0.85 \\
\hline 3 & $0+180$ & 39.2 & -0.37 & 80.1 & 209.2 & -0.18 & 294.2 & 181.2 & 0.02 & 173.4 & 1.22 \\
\hline 4 & $0+200$ & 32.6 & -0.42 & 73.9 & 193.7 & -0.11 & 239.1 & 182.9 & 0.04 & 166.6 & 2.31 \\
\hline 5 & $0+247$ & 36.3 & -0.38 & 77.2 & 225.3 & -0.14 & 296.0 & 245.8 & 0.04 & 222.6 & 0.36 \\
\hline 6 & $0+297$ & 37.8 & -0.35 & 72.7 & 191.2 & -0.11 & 233.8 & 168.8 & 0.02 & 161.2 & 1.64 \\
\hline 7 & $0+320$ & 41.2 & -0.32 & 76.7 & 183.5 & -0.23 & 284.2 & 179.9 & 0.06 & 157.2 & 0.95 \\
\hline 8 & $0+344$ & 31.9 & -0.35 & 64.5 & 164.9 & -0.02 & 171.5 & 198.0 & 0.09 & 155.0 & 0.46 \\
\hline 9 & $0+366$ & 38.3 & -0.31 & 71.4 & 221.2 & -0.11 & 274.8 & 172.6 & 0.05 & 153.6 & 0.78 \\
\hline 10 & $0+390$ & 32.1 & -0.38 & 68.9 & 166.3 & -0.10 & 202.6 & 236.0 & 0.14 & 164.4 & 0.66 \\
\hline Level: II & \multicolumn{11}{|c|}{ HMAC BASE COURSE $(17 \mathrm{~cm}), \mathrm{F}=50 \mathrm{kN}$} \\
\hline 1 & $0+150$ & 37.6 & -0.39 & 87.3 & 201.0 & -0.14 & 270.8 & 198.6 & 0.05 & 173.9 & 1.37 \\
\hline 2 & $0+160$ & 34.3 & -0.43 & 88.8 & 190.9 & -0.08 & 227.3 & 280.1 & 0.12 & 197.5 & 1.16 \\
\hline 3 & $0+180$ & 32.9 & -0.43 & 84.0 & 262.5 & -0.17 & 378.4 & 203.2 & 0.10 & 159.2 & 1.33 \\
\hline 4 & $0+200$ & 31.3 & -0.46 & 85.9 & 190.3 & -0.19 & 287.1 & 185.2 & 0.08 & 150.8 & 1.62 \\
\hline 5 & $0+247$ & 36.1 & -0.40 & 87.1 & 243.1 & -0.11 & 308.7 & 206.9 & 0.05 & 181.3 & 1.06 \\
\hline 6 & $0+297$ & 34.3 & -0.39 & 79.4 & 178.3 & -0.03 & 190.0 & 223.6 & 0.10 & 167.8 & 2.47 \\
\hline 7 & $0+320$ & 34.3 & -0.37 & 78.6 & 126.9 & -0.13 & 169.1 & 196.1 & 0.05 & 167.8 & 1.40 \\
\hline 8 & $0+344$ & 32.5 & -0.38 & 76.1 & 131.0 & -0.06 & 149.5 & 226.4 & 0.10 & 164.9 & 1.48 \\
\hline 9 & $0+366$ & 34.5 & -0.36 & 76.9 & 146.0 & -0.05 & 162.9 & 198.7 & 0.06 & 164.8 & 1.70 \\
\hline 10 & $0+390$ & 36.5 & -0.36 & 82.5 & 137.5 & -0.07 & 160.8 & 233.5 & 0.07 & 185.2 & 1.14 \\
\hline Level: III & \multicolumn{11}{|c|}{ HMAC WEARING COURSE $(8 \mathrm{~cm}), \mathrm{F}=50 \mathrm{kN}$} \\
\hline 1 & $0+150$ & 37.8 & -0.41 & 110.4 & 98.2 & 0.00 & 98.2 & 240.1 & 0.08 & 176.9 & 2.70 \\
\hline 2 & $0+160$ & 33.9 & -0.43 & 110.2 & 78.3 & 0.00 & 78.3 & 255.7 & 0.02 & 231.2 & 2.70 \\
\hline 3 & $0+180$ & 36.1 & -0.41 & 108.1 & 81.3 & 0.04 & 71.1 & 201.1 & 0.06 & 157.6 & 1.82 \\
\hline 4 & $0+200$ & 39.0 & -0.40 & 113.9 & 88.3 & 0.02 & 82.5 & 251.9 & 0.02 & 228.6 & 3.15 \\
\hline 5 & $0+247$ & 37.9 & -0.41 & 113.5 & 86.0 & 0.00 & 86.0 & 229.2 & 0.08 & 168.0 & 1.94 \\
\hline 6 & $0+297$ & 33.3 & -0.38 & 93.1 & 92.7 & 0.05 & 77.7 & 260.2 & 0.11 & 177.8 & 0.52 \\
\hline 7 & $0+320$ & 31.5 & -0.44 & 105.4 & 72.2 & 0.04 & 63.0 & 236.8 & 0.10 & 158.3 & 0.90 \\
\hline
\end{tabular}


Continued of Table 1

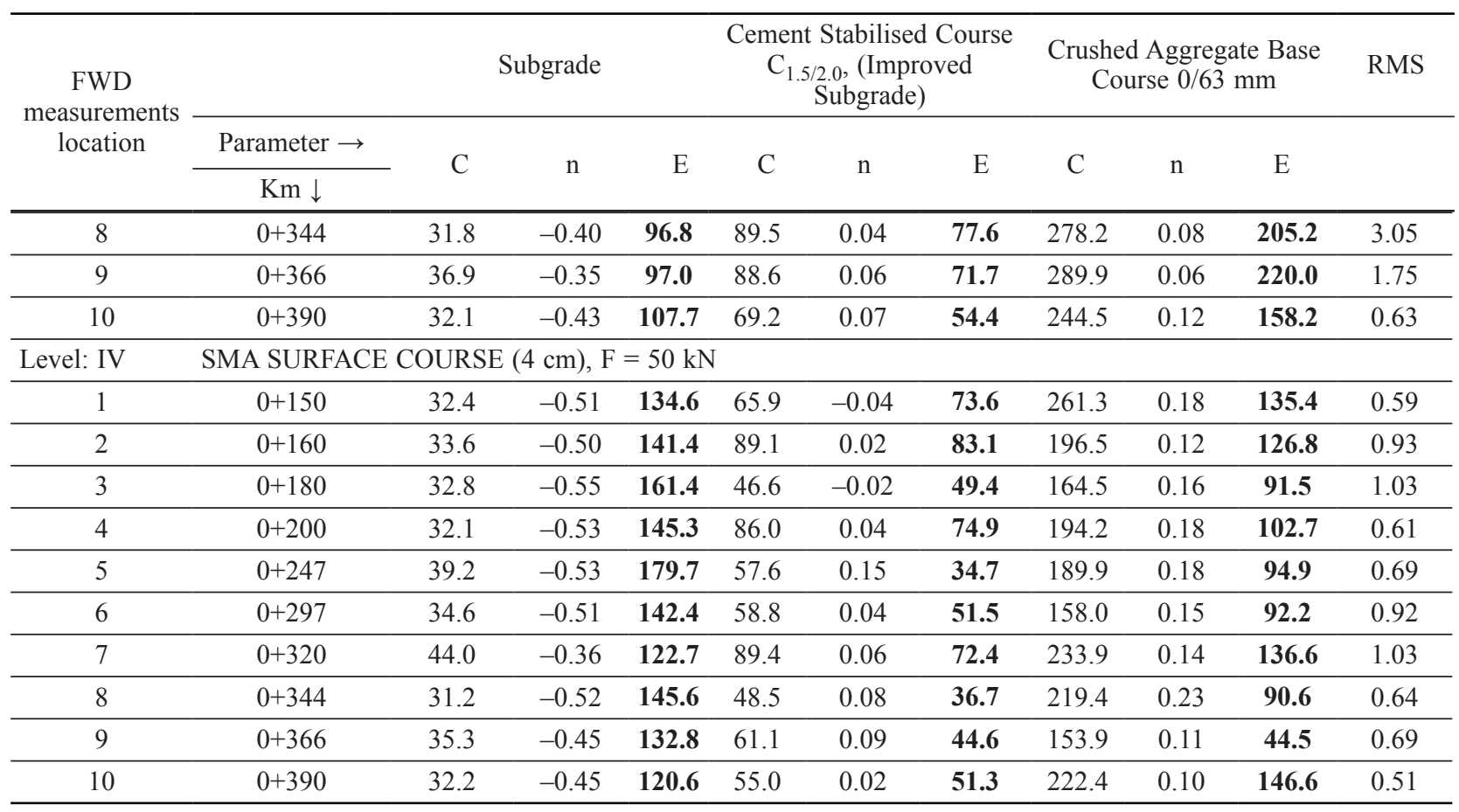

FWD test

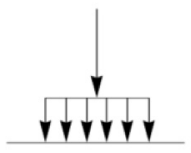

$\mathrm{AC}$

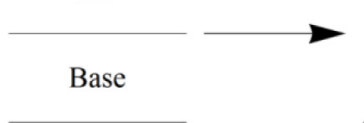

Subgrade

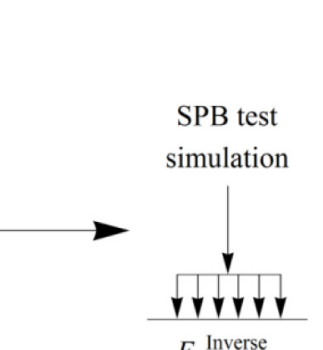

$E_{1 \text { Analysis }}^{\text {Inverse }}$
SPB test

simulation

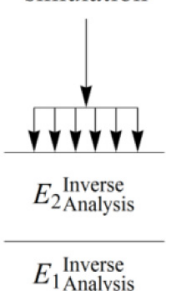

Fig. 6. The general path of analysis in proposed method

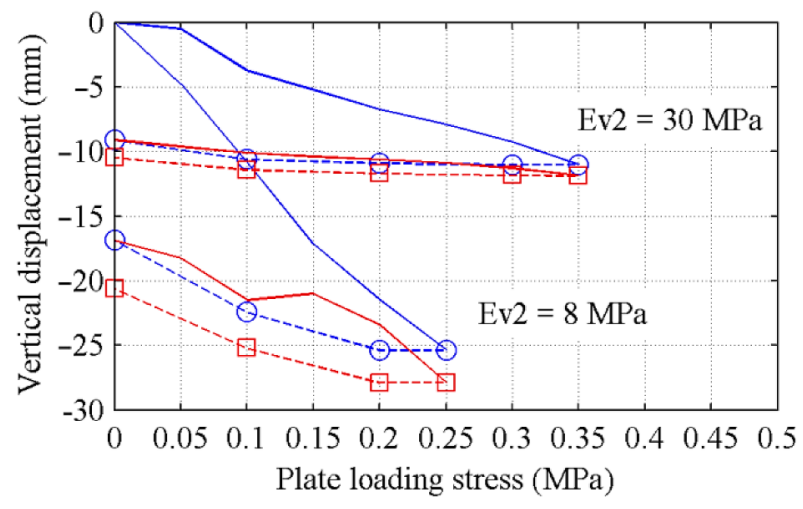

Fig. 7. Extreme plate bearing test results for pavement subgrade of the test section: $0+150.00 \div 0+395.00 \mathrm{~km}$.
Table 2. Mean values of $C$ and $n$ coefficients identified for purposes of plate bearing test simulation on pavement subgrade

\begin{tabular}{ccc}
\hline FWD & \multicolumn{2}{c}{ Mean values of identified parameters } \\
\cline { 2 - 3 } measurements \\
location, Level: & $C$ & $n$ \\
\hline $\mathbf{0}$ & 35.60 & -0.3167 \\
\hline I & 35.13 & -0.3710 \\
\hline II & 34.43 & -0.3970 \\
\hline III & 35.03 & -0.4060 \\
\hline IV & 34.74 & -0.4910 \\
\hline
\end{tabular}

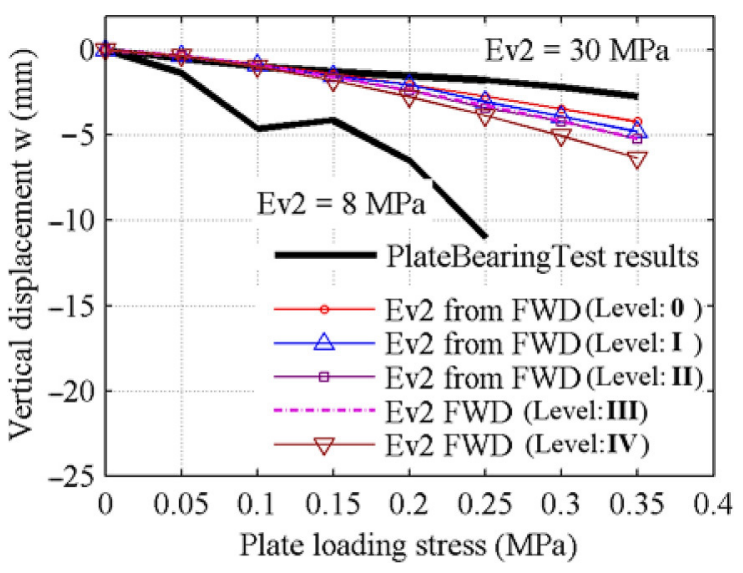

Fig. 8. Curves describing subgrade deformation based on model with stress sensitive layers moduli and extreme deformation curves determined by in-situ plate bearing testing across the entire length of test section 
capacity condition for improved subgrade in this case. The required value of the modulus of deformation located in lower parts of the confidence interval bounding curve was $\mathrm{P}(E v 2 \geq 120 \mathrm{MPa})=0.18$ as per cumulative distribution function plotted for values of the improved subgrade moduli of deformation, based on FWD test points on the

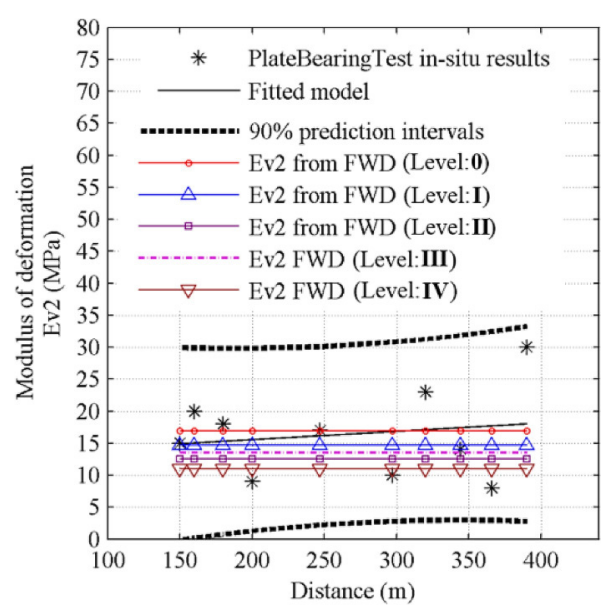

Fig. 9. Ev2 values calculated for assessment the subgrade condition based on values of $C$ and $n$ parameters in a model factoring in stress sensitive layers moduli at different FWD testing locations

Table 3. Mean values of $C$ and $n$ coefficients identified for purposes of plate bearing test simulation for CementStabilised Course and Crushed Aggregate Base Course

\begin{tabular}{ccccc}
\hline FWD & \multicolumn{3}{c}{ Mean values of identified parameters } \\
\cline { 2 - 5 } $\begin{array}{c}\text { measurement } \\
\text { location, } \\
\text { Level: }\end{array}$ & \multicolumn{2}{c}{$C$} & \multicolumn{2}{c}{$n$} \\
\cline { 2 - 5 } & CemStab & AggBase & CemStab & AggBase \\
\hline $\mathbf{0}$ & 171.8 & 260.5 & -0.147 & 0.129 \\
\hline I & 192.8 & 194.2 & -0.112 & 0.050 \\
\hline II & 180.7 & 215.2 & -0.103 & 0.078 \\
\hline III & 84.4 & 248.8 & 0.032 & 0.073 \\
\hline IV & 65.8 & 199.4 & 0.044 & 0.155 \\
\hline
\end{tabular}

surface course (Fig. 12). As far as Ev2 for Crushed Aggregate Base Course is concerned, the same applies to plate bearing test results and simulations.

It could be concluded that in case of FWD testing on asphalt concrete layers, the maximum total pavement layer thickness which would guarantee mean values of plate bearing test simulation being consistent with actual plate bearing test results, should not exceed $25 \mathrm{~cm}$.

Quantile analysis of Ev2 values from FWD measurements (Fig. 4, Level: IV), produces probability very much similar to related improved subgrade SPB test results. The probability we get in such a case is $\mathrm{P}(E v 2 \geq 120 \mathrm{MPa})=0.64$. Bearing in mind heterogeneity of the material, estimated distribution parameters $\mathrm{N}[123,11]$ seem acceptable for purposes of PMS engineering practices.

From quantitative standpoint values of $E v 2$ from FWD measurements on Levels: 0, I, II (Fig. 4) are acceptable. They are highly consistent with plate bearing test results both for Improved Subgrade Course and Crushed Aggregate Base Course, based on obtained probabilities.

\section{Practical application perspective}

The proper pavement diagnosis in PMS procedures should guarantee the selection of effective preventive maintenance. Anyway, as long as the country-specific

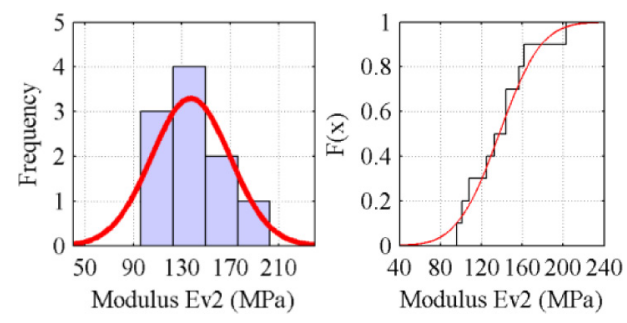

Fig. 11. Histogram of the modulus of deformation values identified using plate bearing test results on crushed aggregate base course (Fig. 4, Level: -I) including continuous and discrete distribution function
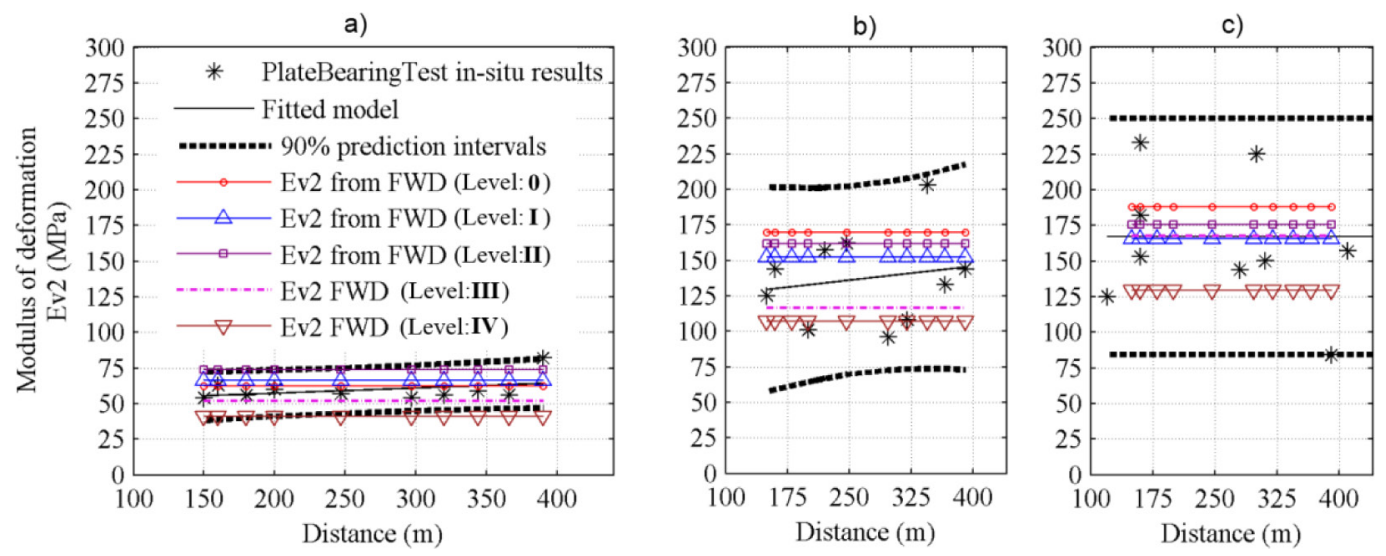

Fig. 10. Ev2 modulus values for both, analytical model (based on mean $C$ and $n$ values, identified from deflection basin measurements) and in-situ SPB test measurements: a) Level -II: Cement-Stabilised Course - STAGE 1; b) Level -I: Crushed Aggregate Improved Subgrade Course - STAGE 2; c) Level 0: Crushed Aggregate Base Course 

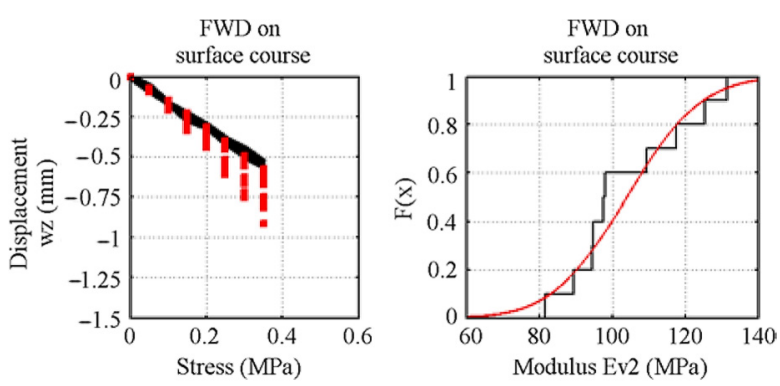

Fig. 12. Example of deformation curve plotted for improved subgrade course (compared against several sample curves based on in-situ SPB test) including cumulative distribution function for values of the modulus of deformation (discrete and continuous)

technical specifications do not define the requirements for limit values of such indicators as e.g. BCI, BDI or, the critical pavement response is the result of imported fatigue criteria usage, search parameters with strong empirical underpinning is highly justified. As well as methods involving the use of DBPs, the proposed method can be the basis of information on the technical state of the pavement subgrade or base courses condition.

The inclusion of $E v 2$ parameter, to a comprehensive visualization of the technical condition of the lower layers of road (Fig. 13), gives to managers a reference quantity, which is the basis for making decisions when building the new pavement structures.

The proposal could be particularly useful in countries where the criterion of minimum value of bearing capacity is given by the secondary deformation modulus parameter.

\section{Conclusions}

The main task in this work was to evaluate the basis of alternative to existing nowadays methods that will allow the road managers use PMS databases more efficiently to a broader extent. Making use of PMS's databases containing all related pavement information including the deflection basin results, this objective can be obtained in the following steps:

- The identification of resilient/stiffness moduli in each layer of pavement model, on basis of inverse analysis and deflection basin measurements.

- Performing the proper pavement model for SPB test simulation considering that all model parameters are known from previous step (resilient and stiffness moduli).

- The Ev2 computation by making use of country specific standard's Eqn (3).

The further following conclusions were drawn from described numerical and on-site experiment:

- The analytical value of the modulus of deformation for subgrade/improved subgrade and aggregate base course pavement layers based on theoretical stiff plate bearing test simulation is consistent with insitu test results provided error level is acceptable in

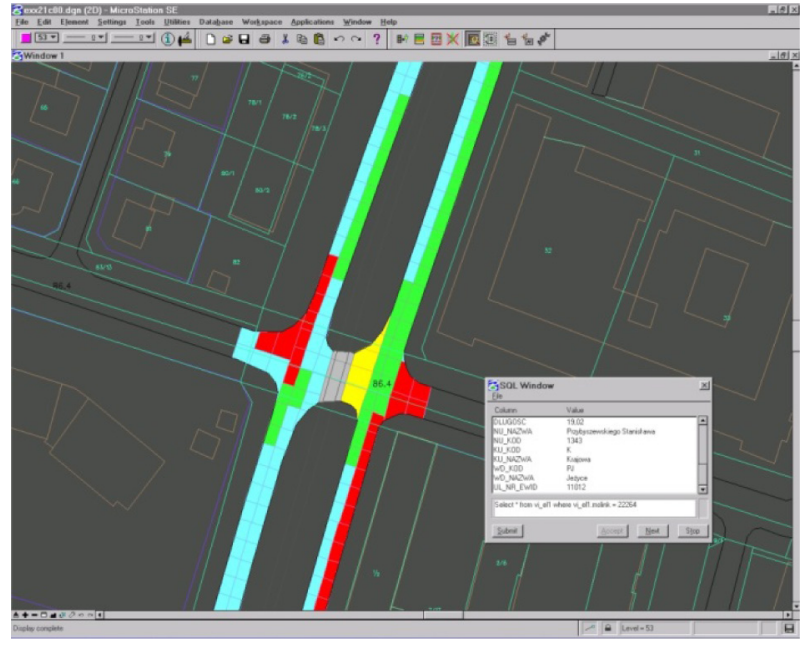

Fig. 13. Pavement condition analysis (Rydzewski, Sztukiewicz 2005) - e.g. the green colour may well indicate the road sections with reduced bearing capacity of subgrade

PMS engineering practice.

- Parameters of subgrade/base pavement layers have to be identified using relationships factoring in impact of stress on values of the stress sensitive layer moduli in order to correctly model the plate bearing test. Two parameter subgrade and base course model produced satisfactory results.

- Since the method uses the generally accepted engineering tools for pavement mechanics analysis, method is not site specific.

- The advantage of using presented method for evaluating subgrade/base pavement layers condition for purposes of PMS is substantial practical experience of using the plate bearing test all over the world. Therefore, reliable criteria for limit states of both subgrade and base courses can be formulated.

- The proposal could be particularly useful in countries where the sanctioned legal criterion of minimum value of bearing capacity is given by the secondary deformation module, thereby giving the PMS road's administrators a reference engineering quantity, which is the basis for making decisions when building the new pavement structures.

- Limited the analysis to that presented in the paper, mean value of $E v 2$ based on FWD deflection data decreases as asphalt concrete layers package thickness increases. Although the thicker package of asphalt concrete layers decreases the accuracy of the identification of $E v 2$, the error is not in excess of $35 \mathrm{MPa}$.

- The maximum total asphalt concrete pavement layer thickness which would guarantee mean values of plate bearing test simulation being consistent with actual plate bearing test results, should not exceed $25 \mathrm{~cm}$.

- In the case when PMS includes the pavements of e.g. Macadam type, to assess their condition one can 
also use the method outlined in the paper. FWD measurements were also taken from the surface of crushed aggregate base course. Then the rootmean-square error RMSE - used in inverse analysis to control accuracy of parameter identification - often exceeds $2 \%$. Anyway, values of secant modulus of deformation for subgrade, improved subgrade and crushed aggregate base course are strongly correlated with plate bearing test results, provided design conditions remain as per this paper.

In summary, the overarching conclusion is that proposed here plate bearing test simulation methodology allows to reliably estimate value of the subgrade and base course modulus of deformation based on FWD deflection data such as taken from PMS databases. Taking into account stress-moduli characterisation for subgrade/base pavement courses, plate bearing test results are most consistent with values of $E v 2$ calculated using FWD deflection data.

\section{References}

Aavik, A.; Paabo, P.; Kaal, T. 2006. Assessment of pavement structural strength by the falling weight deflectometer, The Baltic Journal of Road and Bridge Engineering 1(4): 193-199.

Bertuliene, L. 2012. Assessment, research and use of methods for determining the strength of base courses of road pavement structure, The Baltic Journal of Road and Bridge Engineering 7(3): 228-236.

http://dx.doi.org/10.3846/bjrbe.2012.31

Bertulienè, L.; Laurinavičius, A.; Vaitkus, A. 2010. Research and evaluation of methods for determining deformation modulus of a base course of road pavement, The Baltic Journal of Road and Bridge Engineering 5(2): 110-115. http://dx.doi.org/10.3846/bjrbe.2010.16

Butkevičius, S.; Petkevičius, K.; Kamaitis, I. 2007. Evaluation of flexible road pavement construction state using objective strength criteria, The Baltic Journal of Road and Bridge Engineering 2(2): 61-66.

Chang, C. S.; Cerato, A. B.; Lutenegger, A. J. 2010. Modelling the scale effect of granular media for strength and bearing capacity, International Journal of Pavement Engineering 11(5): 343-353. http://dx.doi.org/10.1080/10298436.2010.488736

Ferreira, A.; Picado-Santos, L.; Wu, Z.; Flintsch, G. 2011. Selection of pavement performance models for use in the Portuguese PMS, International Journal of Pavement Engineering 12(1): 87-97. http://dx.doi.org/10.1080/10298436.2010.506538

Gopalakrishnan, K. 2010. Neural network-swarm intelligence hybrid nonlinear optimization algorithm for pavement moduli back-calculation, Journal of Transportation Engineering 136(6): 528-536. http://dx.doi.org/10.1061/(ASCE)TE.1943-5436.0000128

Huang, L. S; Kang, Y. V. 2010. Nondestructive evaluation of thickness and bearing capacity of roadway pavement structure, International Journal of Pavement Research and Technology 3(6): 326-335.

Kim, M.; Lee, J. H. 2011. Study on nonlinear pavement responses of low volume roadways subject to multiple wheel loads, Journal of Civil Engineering and Management 17(1): 45-54.

http://dx.doi.org/10.3846/13923730.2011.554012
Kim, Y. R. 2002. Use of falling weight deflectometer multi-load data for pavement strength estimation, final report (Report No. FHWA/NC/2002-006), To North Carolina Department of Transportation (Research Project No. HWY-00-4), June 2002.

Le, A. T.; Lee, H. J.; Park, H. M.; Kim, T. W. 2011. Development of Korean pavement design guide for asphalt pavements based on the mechanistic-empirical design principle, The Baltic Journal of Road and Bridge Engineering 6(3): 169-176. http://dx.doi.org/10.3846/bjrbe.2011.22

Park, H. M.; Chung, M. K.; Lee, Y. A.; Kim, B. I. 2011. A study on the correlation between soil properties and subgrade stiffness using the long-term pavement performance data, International Journal of Pavement Engineering 14(2): 146-153. http://dx.doi.org/10.1080/10298436.2011.633167

Rafiei, K.; Kavussi, A.; Yasrobi, S. 2012. Construction quality control of unbound layers based on stiffness modulus criteria, Journal of Civil Engineering and Management 18(1): 5-13. http://dx.doi.org/10.3846/13923730.2011.619328

Rahim, A. M.; George, K. P. 2005. Models to estimate subgrade resilient modulus for pavement design, The International Journal of Pavement Engineering 6(2): 89-96. http://dx.doi.org/10.1080/10298430500131973

Rydzewski, P.; Sztukiewicz, R. 2005. Application of a laser surface analyser for assessment of road pavement evenness, in $3^{\text {rd }}$ International Conference "Modern Technologies in Highway Engineering”, 8-9 September 2005, Poznań, Poland, 222-231.

Šiaudinis, G. 2006. Relationship of road pavement deformation moduli, determined by different methods, The Baltic Journal of Road and Bridge Engineering 1(2): 77-81.

Talvik, O.; Aavik, A. 2009. Use of FWD deflection basin parameters (SCI, BDI, BCI) for pavement condition assessment, The Baltic Journal of Road and Bridge Engineering 4(4): 196-202.

http://dx.doi.org/10.3846/1822-427X.2009.4.196-202

Vaitkus, A.; Laurinavicius, A.; Oginskas, R.; Motiejūnas, A.; Paliukaite, M.; Barvidienė, O. 2012. The road of experimental pavement structures: experience of five years operation, The Baltic Journal of Road and Bridge Engineering 7(3): 220-227. http://dx.doi.org/10.3846/bjrbe.2012.30

Vennapusa, P. K. R.; White, D. J.; Siekmeier, J.; Embacher, R. A. 2012. In situ mechanistic characterisations of granular pavement foundation layers, International Journal of Pavement Engineering 13(1): 52-67. http://dx.doi.org/10.1080/10298436.2011.564281

Westover, T. M.; Labuz, J. F.; Guzina, B. B. 2007. Resilient modulus development of aggregate base and subbase containing recycled bituminous and concrete for 2002 design guide and Mn/Pave pavement design. Final report MN/RC-2007-25. Department of Civil Engineering, University of Minnesota [online], [cited June 2007]. Available from Internet: http://www.lrrb.org/PDF/200725.pdf

Xu, B.; Ranjithan, S. R.; Kim, Y. R. 2002. Case studies: using APLCAP for asphalt pavement layer condition assessment, Submitted for Presentation at the 2003 TRB Annual Meeting and Publication in the Transportation Research Record: Journal of the Transportation Research Board, November 2002.

Yi, J. H.; Kim, Y. S.; Mun, S. H.; Kim, J. M. 2010. Evaluation of structural integrity of asphalt pavement system from fwd test data considering modeling errors, The Baltic Journal of Road and Bridge Engineering 5(1): 10-18. http://dx.doi.org/10.3846/bjrbe.2010.02 
Zaman, M.; Solanki, P.; Ebrahimi, A.; White, L. 2010. Neural network modeling of resilient modulus using routine subgrade soil properties, International Journal of Geomechanics 10(1): 1-12.

http://dx.doi.org/10.1061/(ASCE)1532-3641(2010)10:1(1)

Zavadskas, E. K.; Kaklauskas, A.; Banaitis, A. 2010. Real estate's knowledge and device-based decision support system, International Journal of Strategic Property Management 14(2010): 271-282.

http://dx.doi.org/10.3846/ijspm.2010.20
Zavadskas, E. K.; Liias, R.; Turskis, Z. 2008. Multi-attribute decision-making methods for assessment of quality in bridges and road construction: state-of-the-art surveys, The Baltic Journal of Road and Bridge Engineering 3(3): 152-160.

http://dx.doi.org/10.3846/1822-427X.2008.3.152-160

Andrzej POŻARYCKI. Assistant Professor at the Faculty of Civil and Environmental Engineering at Poznan University of Technology. He has acted as the project manager of many test sections and laboratory experiments for understanding the physical phenomena in road pavements. Through the experience gained in the construction industry, he has successfully combined science with practice. His research interests involve the use of applied mathematics in the practice of civil engineers. 